\section{Testimony to niceness}

\author{
Andrew Whiten
}

Good Natured: The Origins of Right and Wrong in Humans and Other Animals. By Frans de Waal. Harvard University Press: 1996. Pp. 296. \$24.94, £15.95.

A QUESTION for male readers (with whose response women will probably easily empathize): how would you feel about allowing an adult male baboon to reach for your scrotum? At the very least, permitting the act would rest on a very high degree of trust; and the observation that male baboons incorporate such actions into their greeting behaviour has been interpreted as a mutual confirmation of exactly that: trust. These animals are often totally dependent on each other to maintain a coalition against others in their group but, lacking the ability to speak an oath of allegiance, they might be considered to go even further, literally putting their precious reproductive potential in the hand of the other. (It is no accident that 'testimony' shares a linguistic root with 'testicle': biblical oaths were sworn with a hand under the other person's loins.)

Such intimate trust between friends is a far cry from the popular image of these primates as ruthless, self-centred aggressors. Yet this new observation is consistent with a now substantial body of evidence that, as Frans de Waal convincingly shows, is beginning to reveal the many evolutionary foundations of human morality. De Waal disagrees profoundly with the popular view that our morality represents the triumph of cultural constraints over the self-seeking beast within us. For one thing, the pronouncements of sociobiologists such as Richard Dawkins ("if you wish, as I do, to build a society in which individuals cooperate generously and unselfishly towards a common good, you can expect little help from biological nature") and George Williams ("we need all the help we can get in trying to overcome billions of years of selection for selfishness"), are argued to be fundamentally misplaced. That genes are inherently selfish does not mean that individuals must be so. To the contrary, de Waal amasses an impressive array of evidence that animals can genuinely care about the welfare of their companions, even to the extent of showing a "community concern", which is perfectly capable of being favoured by ordinary processes of natural selection.

De Waal achieves two important things in this book. First, he successfully sets out the many ways in which the behaviour of certain species of animal reveals what he calls "the requisites of morality". A crucial ingredient here is the wealth of groundbreaking studies of monkey and ape societies conducted by the author himself over the past 20 years. He describes substantial quantitative studies but also has an eye for the larger, interesting patterns and interpretations that may pass others by. Relying heavily on this database, but supplementing it with the findings of others on various taxa, he deals in turn with evidence for the bases of morality in animal behaviour, including empathy and sympa-

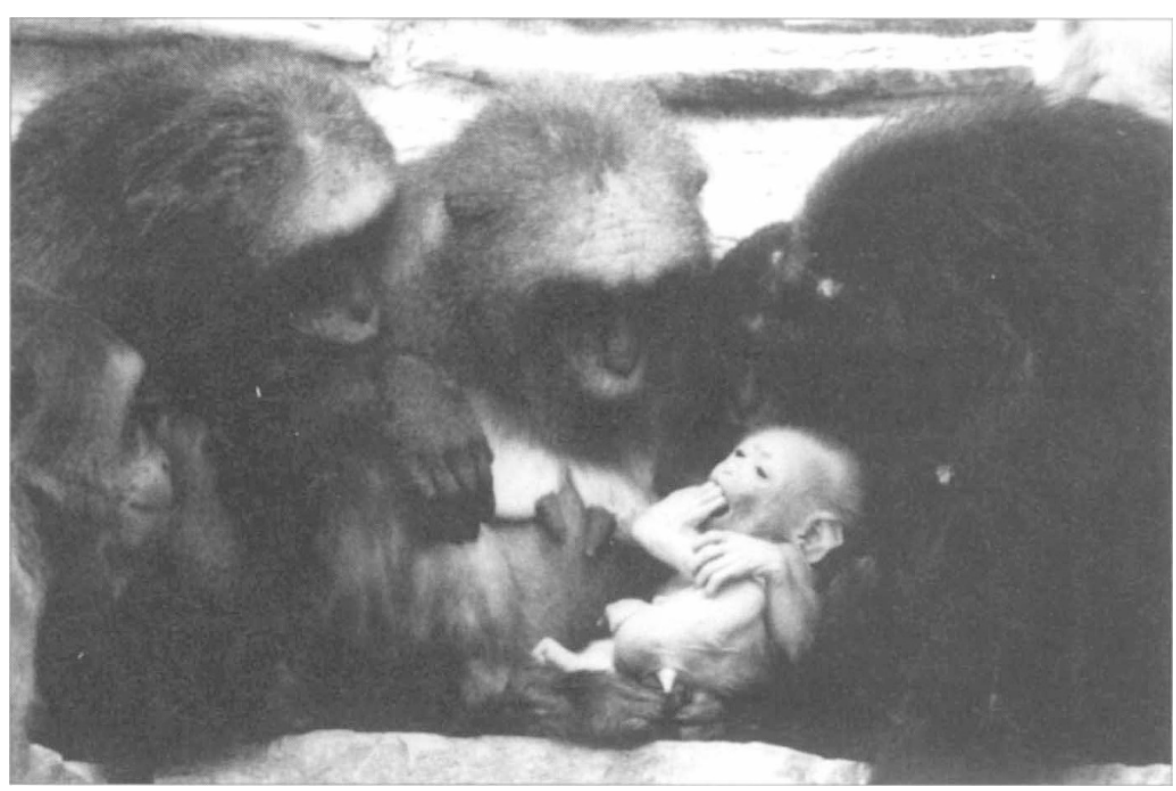

Community concern: a snow-white newborn in its mother's lap, surrounded by other stump-tailed macaques.

thy, reciprocal obligations, maintenance of group harmony and - of particular relevance - signs that animals may take account not merely of how their companions do behave but also of how they ought to behave.

De Waal's second important achievement is to say all this so well that a wide audience will find his book eminently readable. (Extensive technical notes and citations are provided in separate addenda.) Simplistic notions that we have an innate animal kernel that is inherently immoral, or that our moral sense sets us completely apart from nature, abound in writings from psychoanalysis to religion, from tabloid press to cultural anthropology. If many of those espousing such views find they cannot put the book down until they have assimilated much of the evidence, the level of debate should potentially be raised enormously. This is not to say that de Waal's book will end the debate: but it could greatly inform the discussion by laying out a profusion of observations and experimental results that are not widely known, or which have not been the fuzzy question of whether some animals have some of the (pre)requisities for morality, without suggesting where the phylogenetic differences among animals lie.

In attempting to reconstruct the evolutionary precursors to human morality, we would have to home in on the common ancestor shared between ourselves, the chimpanzee and the bonobo. The capacities of those two species would therefore need to be incorporated into the evolutionary modelling process. But de Waal concentrates more on the chimpanzee, which therefore takes on the mantle of an implicit referential model for the most recent, pre-human ancestral state. This reflects not only the emphasis of his own research but also the fact that bonobos are in general much less well understood than chimpanzees. But even the main lines of what we do know receive scant attention. The bias is surprising because de Waal has himself studied bonobos. It leaves unanswered the question of what moral antecedents we should be inferring by taking into account the repertoire of both brought together and interpreted as they are here.

I do, though, have one disappointment. De Waal does not offer even a sketch of a systematic evolutionary account of morality. What moral (or premoral) capacities are shared by the African apes, for example, and might therefore be inferred in our common ancestor? Similar questions can be addressed to wider taxonomic groups, and so on to older ancestral states. Instead, de Waal skips paragraph to paragraph from apes to jackdaws to elephants and back to primates. This makes the book entertaining reading, but gives it the flavour of a preliminary skirmish into 
of our sister genera.

So a skirmish it may be, but it is a challenging and stimulating one that deserves to be widely assimilated and discussed. It may well prove to be an influential landmark in what is starting to look like a pendulum swing, from an era of social evolutionary modelling obsessed with selfishness and Machiavellian manoeuvring, to one that seeks to incorporate evidence of real niceness and community spirit, without a return to naive group-selection theory. $\square$

Andrew Whiten, currently at Emory University, Atlanta, Georgia, USA, is in the School of Psychology, University of St Andrews, St Andrews, Fife KY16 9JU, UK.

\section{Why we age}

Roger Short

Cheating Time: Science, Sex and Ageing. By Roger Gosden. Macmillan: 1996. Pp. 339. £16.99.

THE blue-rinse set must hope against hope that age will not weary them, nor the years condemn them to Shakespeare's Seventh Age of second childishness and mere oblivion, sans teeth, sans eyes, sans taste, sans everything. Fear of ageing has haunted us forever. A popular scientific account of the biological basis for ageing should therefore be welcomed by an evergrowing proportion of the population.

There can be little doubt that lifespan is both one of nature's design constraints and subject to selection. Mike Rose's intriguing experiment with the fruitfly Drosophila shows how easily and rapidly increased longevity can be selected for, so we must ask ourselves what are the selection pressures that have led to such enormous differences in lifespan between species? Why have the tortoise and the hare chosen to run such very different races? Unfortunately, Roger Gosden does not really explore this problem in any depth, even though he opens with an account of Antechinus stuartii, Australia's spectacular marsupial shrew, where all males die at the end of each mating season, broken down by sex rather than age, because celibacy or castration will grant them an extra year of life. Ecologically it is not difficult to see method in their mating madness, but why should the rockfish and the raven, the tortoise and the elephant, the parrot and people live such long lives? There is much that we do not understand.

The human menopause, one of the central themes of this book, also deserves more discussion. Gosden rather lamely concludes that "it is more likely to have crept on to the stage by default". He finds it difficult to see any positive advantage in it, regarding it as "more a handicap than a benefit". Perhaps he would profit from reading Germaine Greer's alternative viewpoint in The Change. Because humans have the longest period of childhood dependency of any animal, it surely makes good sense that the mother should stop producing children well before she is likely to die, so that her lastborn is not seriously disadvantaged by her death. And in many traditional societies, grandmothers are not expected to bear children because they must assume a new role of caring for their grandchildren. For many women, a new life begins at 50 . The shortened human female reproductive lifespan also has important consequences for our mating system. When older men remarry, they almost invariably choose a younger, pre-menopausal wife. The net result is that there are more men who father children by more than one wife than there are wives who have children by more than one husband. In other words, communities that practise serial monogamy are effectively polygynous. This may explain the persistence of such marked sexual dimorphisms in height and body build.

Perhaps the most interesting part of the book, and certainly the most readable, is the historical account of the development of 'rejuvenation therapies', starting in the late nineteenth century with the vain attempt of the 72-yearold Professor Charles-Édouard BrownSéquard in Paris to restore his lost youth by injecting himself with aqueous extracts of guinea-pig and dog testicles. With a whimsical twist, Gosden even dedicates his book to Brown-Séquard, who at least was objective enough to realize that his therapeutic discovery might be an illusion (it was), so he offered to supply his extracts, at his own expense, to any physician who cared to investigate his claims; within a year, 1,200 had taken up his offer and were trying it on their patients. The results were unconvincing, and the method soon fell into disrepute, but it was probably Brown-Séquard's spectacular claims that drew people's attention to the potentially powerful effects of the body's glandular secretions, later called hormones, leading to the development of that eminently respectable scientific discipline, endocrinology.

The scene then shifted from Paris to Vienna, when Professor Eugene Steinach claimed that the body's own production of testosterone was stimulated by vasectomy (it wasn't). Even the poet W. B. Yeats was Steinached at the age of 69 because of his declining productivity. Vasectomy then gave way to testicular grafting, and Serge Voronoff, a French surgeon of Russian Jewish extraction, and his American counterpart, Max Thorek, started a fashion for testicular transplants, politely known as 'monkey glands'. The large testicles of chimpanzees made

\section{IMAGE UNAVAILABLE FOR COPYRIGHT REASONS}

Serge Voronoff: exponent of the testicle.

it possible to treat several men per animal, the grafts being placed in the scrotal $\mathrm{sac}$ of men seeking rejuvenation. With the recent isolation of a HIV-1-type retrovirus from wild chimpanzees, one wonders how close those thoughtless surgeons came to initiating an HIV pandemic immediately after the end of the First World War. It would be interesting to know what Voronoff's and Thorek's many patients eventually died of - perhaps their elderly and debilitated state was a blessing in disguise.

Today we tend to see testosterone more as a poison, responsible for aggression and excessive muscular development, although curiously Gosden regards such claims as unproven. Certainly, castrated men, like Antechinus, seem to live significantly longer, but the therapy has never caught on.

One of the most intriguing speculations about human ageing was in Aldous Huxley's Brave New World, which Gosden does not mention. Huxley advocated the use of "soma", a drug designed for the elderly which would be extremely pleasant to take, even addictive, but which would greatly shorten life expectancy rather like tobacco. As countries move inexorably towards population stabilization, the age pyramid will become more columnar in shape, with ever-increasing numbers of elderly pensioners, living off the economy rather than contributing to it. Those in developed countries will be able to afford expensive palliative care, such as cancer chemotherapy or organ transplantation; most of their lifetime's expenditure on health will occur in the last few years of life, to buy themselves a little extra time at great cost. If life expectancy could be reduced by taking 